\title{
PEMBELAJARAN IPS BERBASIS LITERASI GEOGRAFI DALAM MENUMBUHKAN KARAKTER PEDULI LINGKUNGAN PESERTA DIDIK
}

\author{
Itau Alfiyatirrohmah, Ashfa Nuroniyah, Qurrotun Aini Agustina, \\ Argob Khofya Haqiqi \\ Institut Agama Islam Negeri (IAIN) Kudus \\ ita.alfi99@gmail.com' ainitana73@gmail.com, nuroniyah99@gmail.com, \\ arghobhaqiqi@gmail.com
}

\begin{abstract}
ABSTRAK
Seiring dengan perkembangan zaman, banyak sekali perubahan alam yang terjadi. Perubahan alam tersebut seperti munculnya berbagai macam permasalahan lingkungan yang disebabkan oleh faktor alam maupun tindakan manusia yang tidak bertanggung jawab. Oleh karena itu, karakter kepedulian terhadap lingkungan harus ditanamkan pada setiap individu. Untuk mewujudkan karakter tersebut bisa dilakukan memalui pengelolaan lingkungan yang merupakan bagian dari literasi geografi yang biasanya disampaikan pada pembelajaran IPS yang berbasis literasi geografi. Pembelajaran IPS merupakan salah satu cara tepat untuk menumbuhkan karakter kepedulian lingkungan kepada para siswa. Dimana mata pelajaran IPS tidak hanya menekankan pada masalah-masalah sosial di masyarakat melainkan bersifat terpadu yang juga membahas mengenai pengelolaan lingkungan alam yang mampu menumbuhkan karakter peduli lingkungan, yang nantinya akan menjadi perilaku pada diri setiap peserta didik disetiap harinya. Karya tulis ini dibuat untuk mengetahui bagaimana proses pembentukan karakter peduli lingkungan diterapkan. Karya tulis ini menggunakan metode penggunaan data dengan melalui teknik studi pustaka yang diperoleh melalui berbagai sumber dan jurnal.
\end{abstract}

Kata Kunci: Literasi, geografi, karakter.

\section{ABSTRACT}

Along with the times, a lot of natural changes that happened. Changes in nature such as the emergence of various kinds environmental problems caused by natural factors or human actions that do not to be responsible. Therefore, the character of concern for the environment must be instilled in each individual. For realizing this character can be done through management environment which is part of the usual geographical literacy delivered on social studies learning based on geography literacy. Social studies learning is one of the right ways to foster the character of environmental care for students. Where Social studies subjects not only emphasize social problems at the community is integrated but also discusses about management of the natural environment that is able to foster caring characters environment, which will later become behavior in each student everyday. This paper was made to find out how the process of forming the character caring for the environment is applied. This paper uses methods of data 
usage through library study techniques obtained through various sources and journals.

Keywords: Literacy, geography, characters.

\section{A. PENDAHULUAN}

\section{Latar Belakang Masalah}

Seiring dengan perkembangan zaman, banyak sekali perubahan alam yang terjadi. Perubahan alam tersebut seperti munculnya berbagai macam permasalahan lingkungan yang disebabkan oleh tindakan manusia khususnya oleh peserta didik yang tidak bertanggung jawab. Peserta didik seolah mengabaikan etika lingkungan yang seharusnya menjadi tuntutan dalam berperilaku terhadap lingkungan agar tidak merusak ekosistem alam. Perilaku peserta didik yang belum sadar mengenai kepedulian lingkungan dibuktikan dengan masih banyaknya peserta didik yang membuang sampah sembarangan pada saat jam istirahat.

Hal tersebutlah yang kemudian menyebabkan perlu adanya karakter kepedulian lingkungan pada diri setiap individu. Untuk mewujudkan karakter tersebut bisa dilakukan memalui pengelolaan lingkungan yang merupakan bagian dari literasi geografi yang biasanya disampaikan pada pembelajaran IPS yang berbasis literasi geografi.

Pembelajaran IPS merupakan salah satu cara tepat untuk menumbuhkan karakter kepedulian lingkungan kepada para siswa. Dimana mata pelajaran IPS tidak hanya menekankan pada masalah-masalah sosial di masyarakat melainkan bersifat terpadu yang juga membahas mengenai pengelolaan lingkungan alam yang mampu menumbuhkan karakter peduli lingkungan, yang nantinya akan menjadi perilaku pada diri setiap peserta didik disetiap harinya.

Pendidikan karakter peduli lingkungan tersebut terintegrasi dalam sebuah mata pelajaran IPS. Dimana untuk pendidikan karakter peduli lingkungan tersebut banyak terdapat di dalam materi geografi yang meyangkut lingkungan hidup, sehingga pendidikan peduli lingkungan lebih sering dibahas di mata pelajaran geografi. Pendidikan karakter peduli 
lingkungan tersebut dapat diajarkan di sekolah dan perlu diajarkan sejak dini, yang nantinya diharapkan mampu menanamkan sikap peduli siswa terhadap lingkungan. Kresnawati (2013:298)

\section{Rumusan Masalah}

Berdasarkan latar belakang di atas, pembuatan artikel ini mengacu pada rumusan masalah sebagai berikut:

a. Bagaimana hakikat literasi geoggrafi?

b. Bagaimana model pembelajaran IPS berbasis literasi geografi?

c. Bagaimana strategi pembentukan karakter peduli lingkungan pada peserta didik?

\section{Tujuan Penulisan}

Berdasarkan rumusan masalah di atas, tujuan dari pembuatan artikel ini adalah sebagai berikut:
a. Untuk memahami hakikat literasi geografi.
b. Untuk mengetahui model pembelajaran IPS berbasis literasi geografi.
c. Untuk mengetahui strategi pembentukan karakter peduli lingkungan pada peserta didik.

\section{B. KAJIAN TEORI}

1. Pengertian literasi

Pengertian literasi Literasi atau dalam bahasa inggris literacy merupakan landasan untuk kegiatan belajar sepanjang hayat. Sedangkan menurut kamus online Merriam-Webster, literasi berasal dari istilah latin "literature" dan bahasa inggriss "letter". Yaitu literasi merupakan kualitas atau kemampuan melek huruf atau aksara yang di dalamnya meliputi kemampuan membaca dan menulis. Menurut kurikulum Ausstralia, pengertian literasi meliputi pengetahuan dan keterampilan siswa dalam mengaksses, memahami, manganalisis, dan mengevaluasi informasi serta membuat makna dalam fikiran untuk mengekspresikan emosi, memberikan ide dan opini, berinteraksi dan berpartisipasi dalam kegiatan di sekolah maupun di luar sekolah. (Sugiyanto:2017) 


\section{Makna Literasi Geografi}

Dalam Novarlita (2013:276) menurutnya, literasi geografi adalah istilah baru untuk ide lama yang terdiri dari tiga komponen: interaksi, interkoneksi, dan implikasi. Model pembelajaran literasi geografi adalah kemampuan untuk menggunakan pemahaman dan penalaran geografis untuk membuat keputusan yang jauh jangkauannya. Literasi geografi menawarkan suatu cara untuk membangunn kecerdasan peserta didik melalui pembelajaran dengan memannfaatkan masalah keruangan yang terjadi di permukaan bumi. Model pembelajaran IPS dengan menggunakan tekhnik literasi geografi itu dilakukan dengan menggunakan tiga tahapan dan pengembangan, yaitu: 1) studi pendahuluan yang meliputi studi literatur, studi lapangan dan penyusunan desain awal. 2) pengembangan model yang meliputi uji coba terbatas, dan uji coba luas. 3) validasi model yang menggunakan metode eksperimen dan sampel kontrol.

\section{Konsep IPS}

IPS merupakan perpaduan dari pilihan konsep ilmu-ilmu sosial seperti ssejarah, geografi, ekonomi, antrhopologi, budaya dan sebagainya yang dipruntukkan sebagai pembelajaran pada tingkat persekolahan. Sedangkan menurut A.Kosasih Djahiri, IPS merupakan ilmu pengetahuan yang memadukan sejumlah konsep pilihan dari cabang-cabang ilmu sosial dan ilmu lainnya kemudian diolah berdasarkan prinsip-prinsip pendidikan.

4. Pembelajaran IPS

Pada dasarnya,pembelajaran IPS merupakan pelajaran yang bersifat terepadu yang bertujan agar mata pelajaran tersebut lebih bermakna bagi peserta didik, sehingga pengorganisasian materi dan bahan pelajaran disesuaikan dengan lingkungan, karakteristik, dan kebutuhan peserta didik. Dengan begitu, peserta didik dapat menguasai dimensi-dimensi pembelajaran di sekolah, yaitu: menguasai pengetahuan, keterampilan, skip dan nilai, serta bertindak. Sapriya (2009:6). 


\section{METODE PENELITIAN}

Metode yang digunakan dalam penulisan artikel ini adalah dengan melakukan studi pustaka atau tekhnik kepustakaan. Karena artikel ini tidak menggunakan metode penelitian di lapangan, jadi kami mencari sumber penulisan dan bahan-bahan tentang pembelajaran IPS berbasis literasi geografi ini dari jurnal-jurnal. Berbagai referensi dari jurnal terssebut yang nantinya akan kami jadikan acuan dalam penulisan artikel dan sekaligus untuk memperkuat tulisan yang akan kami buat.

\section{HASIL DAN PEMBAHASAN}

\section{Hakikat Literasi Geografi}

Dalam Ruhimat (2017:79-80) menurutnya, istilah literasi geografi berasal dari "geographic literacy" yang sering di singkat menjadi "geoliteracy". Ada banyak definisi literasi geografi yang disampaikan oleh para ahli. Salah satu aliran pemikir geografi menyamakan literasi geografi dengan kemampuan untuk menemukan tempat pada peta, yaitu pengetahuan mengenai tempat lokasi (place location knowledge/PLK) dengan alasan bahwa PLK menjadi fondasi atau akar dalam studi geografi. Istilah literasi geografi ini muncul pertama kali dari National Geographic yang mana organisasi ini dirilis berbagai media untuk membantu menjelaskan konsep literasi geografi kepada masyarakat umum. National Geographic Society mengatakan bahwa geo literacy is the ability to reason about earth systems and interconnections to make far-reaching decisions. Pattison mendefinisikan bahwa literasi geografi adalah empat anggapan yang sudah populer, yang menjadi pondasi geografi yaitu studi tata ruang, daerah, manusia-lahan, dan ilmu bumi. Sedangkan para peneliti dari dua asosiasi geografi mengidentifikasi bahwa literasi geografi adalah "identified five themes-movement, region, human-environment interaction, location, and place", yang artinya kajian mengenai lima tema yang umum pada geografi yaitu gerakan, region, interaksi manusia dan lingkungan, lokasi, dan tempat. 
Dilain pihak, Hunter mengatakan pula bahwa geographic literacy or geo-literacy is a broad term that encompasses the overall competence of an individual's geographic knowledge. Literasi geografis bukan hanya sekedar menghapal nama-nama lokasi, nama sungai, gunung dan laut, melainkan merupakan kemampuan seseorang secara kritis terhadap kondisi lingkungan sekitar. Literasi Geografi juga menyangkut pemahaman interaksi antara manusia terhadap lingkungan dalam berbagai skala beserta konsekuensinya. Edelson menjelaskan bahwa geo-literacy enables people to steer away from choices that will be costly themselves and others. Selanjutnya Edelson menambahkan pula bahwa the term in the field of geography education is combined by the so called three is interaction, interconnections and implication. Interaksi, pada prinsipnya berupa pemahaman mengenai hubungan antara lingkungan alam dengan manusia, artinya berbagai sikap dan perilaku manusia akan mempengaruhi eksistensi lingkungan alam. Interkoneksi, merupakan pemahaman terhadap suatu tempat yang satu dengan tempat yang lainnya memiliki persamaan dan perbedaan karakteristik geografis yang saling terkait. Implikasi, merupakan pengambilan keputusan tepat yang berbasis kondisi geografis.

Menurut American Geographical Society geography is the science of space and place on Erath's surface, its subject matter is the physical and human phenomena that make up the world's environment and places. Jadi dapat disimpulkan bahwa literasi Geografi merupakan pengetahuan seseorang terhadap ruang, termasuk didalamnya dapat menunjukkan lokasi suatu tempat, serta sensitifitas terhadap keberadaan lingkungan.

\section{Model Pembelajaran IPS Berbasis Literasi Geografi}

Dalam Nisa' (2017:9) menurutnya, model pembelajaran berbasis literasi geografi merupakan strategi baru dalam pembelajaran IPS yang dihasilkan melalui proses penelitian dan pengembangan. Selain itu, pembelajaran berbasis literasi geografi juga bisa dikatakan sebagai proses pembelajaran yang didalamnya ada penggambaran kemampuan untuk mengekspresikan pengetahuan. Materi pelajaran geografi dasar yaitu 
kemampuan untuk menunjukan lokasi pada peta, pemahaman keterhubungan tentang manusia dan lingkungan, serta pengelolaan lingkunggan (ekologi).

Adapun model pembelajaran IPS berbasis literasi geografi ini menawarkan alternatif dalam upaya membangun kecerdasan peserta didik melalui pembelajaran dengan memanfaatkan masalah keruangan yang terjadi di bumi dan diaplikasikan dengan materi pembelajaran di kelas. Adapun tujuan dari model pembelajran berbasis literasi geografi yaitu untuk membangun kecerdasan ruang pesesrta didik sekaligus meningkatkan penguasaan materi IPS. Maksud dari kecerdasan ruang yaitu suatu aktivitas mental yang bertujuan untuk membentuk cara berfikir, berkomunikasi, dan membuat solusi terhadap segala masalah keruangan yang dimulai dari pengenalan objek melalui persepsi di lingkungannya. Kecerdasan ruang dalam pembeajaran IPS berperan penting dalam menjawab tantangan globalisasi.

Kondisi pembelajaran IPS yang berkaitan dengan menumbuhkan kepedulian lingkungan terhadap peserta didik yaitu seorang guru IPS betul-betul harus memahami dan menguasai secara substansi tentang materi IPS yang bertujuan untuk menumbuhkan karakter peduli lingkungan.

\section{Strategi Pembentukan Karakter Peduli Lingkungan}

Karakter merupakan watak yang melekat pada diri seseorang, dan watak tersebut nantinya akan membentuk perilaku orang yang bersangkutan. Karakter tidak bisa muncul dengan sendirinya, melainkan melalui proses pembentukan yang dilakukan secara bertahap. Sedangkan karakter peduli lingkungan merupakan salah satu karakter yang harus ditanamkan sejak dini kepada peserta didik. Hal tersebut dilakukan agar dapat menjadikan peserta didik memiliki rasa tanggung jawab, kesadaran, serta kepekaan terhadap lingkungannya. kesadaran terhadap lingkungan hidup merupakan aspek yang penting dalam pengelolaan lingkungan hidup, karena keesadaran terhadap lingkungan hidup merupakan bentuk 
kepedulian seseorang terhadap kualitas lingkungan. Adapun peserta didik yang sejak dini tidak ditanamkan karakter peduli lingkungan, maka dapat menjadikan peserta didik tidak memiliki karakter tersebutdan pada akhirnya akan berdampak pada perilakunya yang akan cenderung menyimpang dengan lingkungan.

Dalam Utaya (2017:971) menurutnya, saat ini, dalam dunia pendidikan karakter menjadi hal utama yang perlu dikembangkan pada diri siswa. Pembangunan karakter dalam pendidikan karakter itu merupakan suatu keharusan karena pendidikan tidak hanya menjadikan peserta didik menjadi cerdas juga mempunyai budi pekerti serta sopan santun. Seperti yang terdapat dalam kurikulum 2013, bahwa karakter menjadi hal utama sebelum pengetahuan dan keterampilan. Berbagai cara telah dilakukan dalam dunia pendidikan untuk membentuk karakter siswa tersebut. Beberapa cara diantaranya seperti dengan menyelipkan pendidikan karakter dalam proses pembelajaran di kelas, atau juga bisa dengan melalui kegiatan di luar pendidikan formal seperti melalui kegiatan ekstrakulikuler.

Dalam Al-Anwari (2014:237-240) menurutnya, adapun strategi pembentukan karakter peduli lingkungan terhadap peserta didik dapat dilakukan melalui berbagai cara, diantaranya:

a. Pembentukan karakter peduli lingkungan melalui kegiatan belajar mengajar.

Adapun pembentukan karakter melalui kegiatan belajar mengajar ini dibagi menjadi dua pola:

1) Pertama, strategi pembentukan karakter peduli lingkungan melalui muatan lokal pendidikan lingkungan hidup (PLH) yang dijadikan sebagai muatan lokal wajib yang diajarkan pada semua kelas dan diberi beberajam dalam setiap minggunya.

2) Kedua, strategi pembentukan karakter peduli lingkungan dilakukan melalui pengintegrasian muatan lokal pendidikan lingkungan hidup ke dalam mata pelajaran lain atau tema lain (pembelajaran tematik 
pada kurikulum 2013) yang mempunyai keterkaitan dengan muatan lokal PLH tersebut.

b. Strategi pembentukan karakter peduli lingkungan dengan menggunakan kegiatan di luar jam pelajaaran formal, seperti melaksanakann kegiatan ekstrakulikuler yang dekat dengan lingkungan.

c. Strategi pembentukan karakter peduli lingkungan melalui penguatan pendidikan karakter dari keluarga. Strategi tersebut bisa dilakukan melalui kegiatan pertemuan peserta didik pada saat pembagian raport. Momen tersebut bisa dimanfaatkan para guru untuk merangkul para orang tua peserta didik agar bisa satu visi dan misi dengan sekolah dalam mendidik para peserta didik tersebut, khususnya terkait dengan pembentukan karakter peduli lingkungan di rumah.

d. Strategi pembentukan karakter peduli lingkungan melalui budaya sekolah.

Dalam Mulyana (2009:177) menurutnya, strategi pembentukan karakter peduli lingkungan melalui budaya sekolah yaitu dilakukan melalui kegiatan rutin harian, mingguan, dan sewaktu-waktu. Kegiatan rutin harian yaitu meliputi piket harian siswa, adapun tugas piket harian siswa terbagi menjadi dua yaitu menjaga dan membersihkan lingkungan kelas serta menjaga dan merawat taman yang berada di depan kelasnya masing-masing. Sedangkan kegiatan rutin mingguan adalah seperti jum'at bersih. Kegiatan jum'at bersih tersebut dilaksankan setiap seminggu sekali. Sedangkan kegiatan rutin yang bersifat sewaktu-waktu yaitu seperti hari-hari lingkungan hidup yang waktu pelaksanaannya menyesuaikan dengan tanggal dan hari peringatan lingkungan hidup tersebut.

\section{E. KESIMPULAN}

Model pembelajaran IPS berbasis literasi geografi yaitu salah satu model pembelajaran yang menawarkan alternatif dalam upaya membangun 
kecerdasan peserta didik melalui pembelajaran dengan memanfaatkan masalah keruangan yang terjadi di bumi dan diaplikasikan dengan materi pembelajaran di kelas. Adapun tujuan dari model pembelajran berbasis literasi geografi yaitu untuk membangun kecerdasan ruang pesesrta didik sekaligus meningkatkan penguasaan materi IPS.

Hal yang ditekankan dalam pembelajaran IPS yang berkaitan dengan upaya menumbuhkan karakter peduli lingkungan peserta didik yaitu seorang guru harus bisa memahami secara substansi bahwa materi IPS yang bekaitan dengan menumbuhkan karakter peduli lingkungan. Guru tersebut harus bisa menggabungkan materi pembelajaran IPS di kelas dengan kenyataan yang berada di lingkungan guna mencapai tujuan untuk menumbuhkan karakter peduli lingkungan. Guru tersebut bisa memanfaatkan lingkungan sekitar sebagai sumber belajar.

Ada banyak cara atau strategi yang bisa dilakukan untuk menumbuhkann karakter peduli lingkungan peserta didik. Berbagai cara yang telah dilakukan dalam dunia pendidikan untuk membentuk karakter siswa tersebut diantaranya seperti dengan menyelipkan pendidikan karakter dalam proses pembelajaran di kelas, atau juga bisa dengan melalui kegiatan di luar pendidikan formal seperti melalui kegiatan ekstrakulikuler

\section{DAFTAR PUSTAKA}

Al-anwari, Amirul Mukminin. "Strategi Pembentukan Karakter Peduli Lingkungan Di Sekolah Adiwijaya Mandiri”. Jurnal Pendidikan, Vol. XIX, No.2 (2014)

Kresnawati, Novia. Korelasi Kualitas Pembelajaran Geografi dan Hasil Belajar terhadap Sikap Peduli Lingkungan Siswa Kelas XII IPS SMAN 1 Ponorogo. Jurnal Pendidikan. Vol.1 No.3 (2013)

Mulyana, R. Penanaman Etika Lingkungan Melalui Sekolah Peduli dan Berbudaya Lingkungan. Jurnal Tabularasa. PPs United, Vol.6 No.2 (2009) 
Nisa', Jakiatin dkk. "Identifikasi Pembelajaran IPS Berbasis Literasi Geografi Dalam Menumbuhkan Karakter Peduli Lingkungan Peserta didik”. SOSIO DIDAKTA: Social Science Education Journal, Vol.4 No.1 (2017)

Novarlita, Irena. Model Pembelajaran Berbasis Litersi Geografi dalam Upaya Membangun Kecerdasan Ruang Peserta Didik. Bandung: Repository Universitas Pendidikan Indonesia. 2013.

Ruhimat, Mamat. "Peningkatan Pemahaman Wawasan Kebangsaan Melalui Literasi Geografis". Prosiding Seminar Nasional Tahunan Fakultas Ilmu Sosial Universitas Negeri Medan, Vol.1 No.1 (2017).

Sugiyanto, dkk. Studi Tingkat Kepemahaman Guru IPS SMP tentang Literasi Geografi. Jurnal Pendidikan Ilmu Pengetahuan Sosial, Vol.26 No.2 (2017).

Supriya, dkk. Pendidikan IPS Konsep dan Pembelajaran. Bandung: PT. Rosakarya. 2009

Utaya, Sugeng, dkk. "Memebentuk Karakter Peduli Lingkungan Melalui Komunitas Pelajar Peduli Lingkungan Hidup (KPPLH)". Prosiding TEP \& PDs Transformasi Pendidikan Abad 21, Tema 7 No.4 (2017). 